\title{
Batch Sorption Experiments on Recycling Building Waste to Treat Total Iron in Landfill - Leachate
}

\author{
K. Vinayakamoorththy and W.K.C.N. Dayanthi
}

\begin{abstract}
Building waste, namely Concrete Waste (CW), Brick and Mortar Waste (BMW), Flooring Waste (FW), and Roofing Waste (RW), was used as an adsorbent of total iron contained in landfill-leachate. First, kinematic batch sorption experiments were conducted to optimize the contact time, and thereafter adsorption isotherm experiments were conducted to optimize the adsorbent mass. Next, the effects of the initial iron concentration, initial $\mathrm{pH}$ of the landfill-leachate and temperature on the removal efficiency of total iron was studied. About $90 \%$ removal of total iron was possible in about $12 \mathrm{~h}, 2 \mathrm{~h}, 8 \mathrm{~h}$ and $8 \mathrm{~h}$ for CW, FW, BMW and RW, respectively, under batch test conditions. The maximum adsorption of total iron occurred at adsorbent dosages of $8 \mathrm{~g}, 10 \mathrm{~g}, 6 \mathrm{~g}$ and $10 \mathrm{~g}$ for CW, FW, BMW and RW with the removal efficiencies $99.6 \%, 97.8 \%, 97.9 \%$ and $95.3 \%$, respectively. The removal efficiency was proportional to the initial total iron concentration and decreased with increase of temperature. The adsorption data follows the Langmuir adsorption isotherm model the best. The adsorption capacity of total iron on CW, BMW, FW and RW were $0.43,0.84,0.17$ and $0.43 \mathrm{mg} / \mathrm{g}$, respectively.
\end{abstract}

Keywords: Landfill- leachate, Building waste, Total iron, Adsorption, Adsorbent, Isotherm

\section{Introduction}

At present, scarcity of water is the most significant water problem in the world [1]. The groundwater reservoir is the largest, high quality, usable and reliable water source on earth [2]. It can contribute immensely to solve the problem of water scarcity. However, the massive urbanization continuously releases toxic contaminants into the groundwater reservoir by domestic, industrial and mining actions [3], causing environmental pollution. Many kinds of pollutants occur such as factorial waste, inorganic and organic chemicals, radioactive substances, nutrients and heat [4]. Especially, the priority pollutant of groundwater is landfill leachate [5]. Furthermore, in developing countries, the contamination of ground and surface water by landfill-leachate is a significant issue due to the large number of uncontrolled and semi-controlled dumpsites. The leachate is generated from rain water passing through the solid waste. It consists of different organic and inorganic compounds and heavy metals ( $\mathrm{Fe}, \mathrm{Cu}, \mathrm{Cd}, \mathrm{Mn}, \mathrm{Zn}, \mathrm{Pb}$ and $\mathrm{As}$ ), which may be toxic to the living organisms and simply alter the present ecology [6]. The heavy metals can inhibit the biodegradation of organic contaminants. Zhao et al. [7] mentioned that most of heavy metal ions are toxic to living organisms; these metal ions are non-degradable and are persistent in the environment; therefore, the elimination of heavy metal ions from wastewater is important to protect public health.

Therefore, the proper treatment of landfillleachate and groundwater contaminated by landfill-leachate is essential. Hence, in order to increase the treatment efficiency, new technologies have been developed over the past years. Many technologies are still limited by large cost, extensive area required and continuous addition of the toxic elements. However, the practical application of most of these techniques have issues due to the fact that the packing materials such as ZVI (Zero Valant Ion), Halogenated Aliphatic Hydrocarbons (HAH), activated carbon, zeolite, appetite and etc., which are high in cost and produce toxic sludge [8].

\footnotetext{
Miss. K. Vinayakamoorththy, BSc Eng (Hons)

(Ruhuna), Student Member of IESL.

Email:nvmgayathry20@gmail.com

(D) https://orcid.org/0000-0002-9349-6994
}

Eng. (Dr.) W.K.C.N. Dayanthi, BSc Eng (Peradeniya), MEng (Moratuwa), MEng (AIT), DEng (Kyoto), MIE (SL), Senior Lecturer, Department of Civil and Environmental Engineering, Faculty of Engineering, University of Ruhuna, Sri Lanka.

Email:neetha02@gmail.com

(iD) https://orcid.org/0000-0003-3309-8430 
Hence, it is essential to introduce low-cost and eco-friendly innovative packing materials in the reactive/filter media beds of these treatment systems. At present, much research has been carried out on such packing materials. Among them, following materials have been used for batch sorption experiments to find out their total iron removal potentials: Chitosan beads [9], Chicken litter bio char [10], Rice husk [11], Fly ash [11] and Coconut husk [12].

Building waste consists of concrete, brick and mortar, flooring and roofing waste. Portland cement is a primary component in building waste. It is produced by heating lime, iron, silica, and alumina to extreme temperatures. Normal Portland cement consists of superplasticizers. Admixture, pigments, fibers and polymers have the ability to bind with heavy metals. Aggregate can adsorb the metals, which are bound together with hydrated cement. The major component of brick is clay. It consists of some minerals, which have the ability to remove high concentrated $\mathrm{Pb}^{2+}$. Zhao et al. [7] stated that clay minerals have high sorption, ion exchange and expansion properties; they are widely used to adsorb all kinds of pollutants from large volumes of aqueous solutions; and a lot of studies are focused on sorption of heavy metal ions on clay minerals. Cement mortar consists of sodium sulphate and magnesium phosphate. Further, it contains superplasticizers. Flooring tiles consist of crystalized minerals, quarts and carbonate, which have higher rates of heavy metal removal. Roofing tiles are very thick in hydrocarbon content, and consist of chemically reactive catalysts.

Hence, owing to a wide range of both chemical and mechanical properties, building waste seems to be a potential reactive/filter packing material in landfill-leachate treatment systems. In selecting a suitable reactive/filter material, following factors are the criteria the selection should be based on: reactivity, stability, availability and cost, and hydraulic performance [13]. Building waste seems to satisfy above criteria. On the other hand, building waste has become a controversial solid waste in many countries because of lack of suitable disposal sites. Therefore, recycling building waste as a reactive/filter packing material in landfillleachate treatment systems would be a solution for its disposal issue.

Hence, the present study was carried out to find a solution for both the above issues by investigating the potential of building waste to be used as a reactive/filter packing material in landfill-leachate treatment systems using batch sorption experiments. Sorption is considered as a very effective and economical process for metal ion removal from wastewaters [7]. The first objective was to optimize the contact time and adsorbent dosage. The second objective was to obtain the adsorption capacity for the optimum conditions and obtain the adsorption isotherms. The third objective was to find out the variation of the removal efficiency with the change of initial concentration, temperature and initial $\mathrm{pH}$.

\section{Methodology}

\subsection{Preparation of Adsorbents}

Four types of building waste \{concrete waste $(\mathrm{CW})$, brick and mortar waste (BMW), roofing waste (RW) and flooring waste (FW) \} were collected from several demolition sites in Galle, Sri Lanka. CW consists of concrete and reinforcement, BMW contains bricks and mortar, FW consists of floor tiles and dried cement slurry, and RW contains roof tiles without asbestos and timber. First, these materials were washed with tap water to remove residues from the surfaces. After that, grinding and sieving were done manually to get the desired particle size $(0.425 \mathrm{~mm})$. The selected portion was washed with de-ionized water using $0.45 \mu \mathrm{m}$ glass filter papers, and dried at $100{ }^{\circ} \mathrm{C}$ for $24 \mathrm{~h}$. Figure 1 illustrates the building waste samples used for the batch sorption experiments.

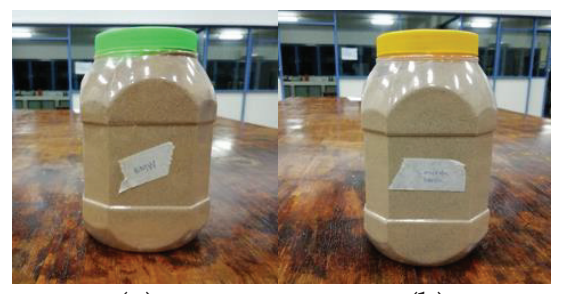

(a)

(b)

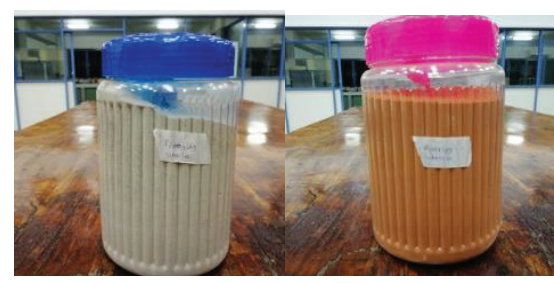

(c)

(d)

Figure 1 - Building Waste Samples (a) BMW; (b) CW; (c) FW; (d) RW 


\subsection{Batch Sorption Experiments}

The raw leachate collected from an inorganic waste landfill site was used as the adsorbate. The initial concentration of total iron, $\mathrm{pH}$, Oxidation Reduction Potential (ORP) and conductivity in the raw leachate were $20.6 \mathrm{mg} / l, 8.09,236 \mathrm{mV}$ and $18.9 \mu \mathrm{s} / \mathrm{cm}$, respectively. The raw leachate was kept in a refrigerator after collection until the experiments were conducted. It was added with conc. $\mathrm{HNO}_{3}$ to bring $\mathrm{pH}$ equal to 2 before being refrigerated in order to prevent any loss of heavy metals during the storing period.

The batch sorption experiments were of two types, namely, kinematic experiments and adsorption isotherm experiments. In the kinematic experiments, the optimum contact time for each adsorbent (CW, BMW, RW and FW) was obtained. Figure 2 shows the containers of supernatants resulted in a kinematic experiment. Then, in the adsorption isotherm experiments, the adsorbent dosage for each material was optimized keeping the contact time at the respective optimum value obtained in the previous experiment. These experiments were conducted in a series of $250 \mathrm{ml}$ conical flasks stirred at $400 \mathrm{rpm}$ at $25{ }^{\circ} \mathrm{C}$. The experimental ranges of contact time and adsorbent dosages were $1 \mathrm{~h}-12 \mathrm{~h}$, and $2 \mathrm{~g}-15 \mathrm{~g}$, respectively. Next, the effect of the initial iron concentration (varied between $25 \mathrm{mg} / \mathrm{l}$ - $200 \mathrm{mg} / \mathrm{l}$ ), temperature (varied between $25^{\circ} \mathrm{C}-60{ }^{\circ} \mathrm{C}$ ) and initial $\mathrm{pH}$ (varied between 2 - 8) variation on the removal efficiency by BMW were investigated using batch sorption experiments keeping both the contact time and adsorbent dosage constant at the respective optimum values. Finally, adsorption isotherms were plotted for the adsorption isotherm experiments conducted for each material. The adsorption capacity was obtained for the optimum conditions of each adsorbent.

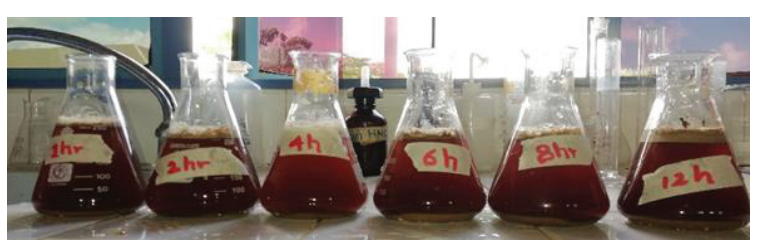

Figure 2 - The Samples of Supernatant of a Kinematic Experiment

\subsection{Total Iron Analysis}

The concentrations of Total Iron were determined by UV -VIS spectrophotometer (UV mini - 1240) using ultra violet radiation in accordance with the Standard Methods of the Examination of Water and Wastewater [14]. The final concentration of each sample was the aaverage values of three replicates.

\subsubsection{Preparation of the Stock Solution and the Standards}

The stock solution of iron was prepared by dissolving $0.7022 \mathrm{~g}$ of Ferrous Ammonium Sulphate in distilled water by adding $5 \mathrm{ml}$ of $40 \%$ sulphuric acid. $0.2 \%$ Potassium Permanganate was added drop by drop until the color became pink. Then, the solution was diluted with distilled water up to $1 l$. The standard solutions of desired concentration values $(0.1 \mathrm{mg} / \mathrm{l}-3.0 \mathrm{mg} / \mathrm{l})$ were prepared by successive dilution of the corresponding amounts of the stock solution. Figure 3 depicts the standard solutions prepared from the stock solution.

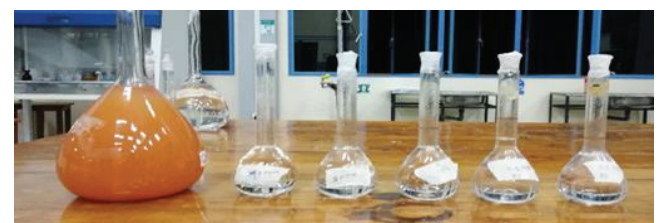

Figure 3 - Standard Solutions

\subsubsection{Sample Preparation}

$50 \mathrm{ml}$ of the supernatant from each batch experiment sample was taken into a $150 \mathrm{ml}$ flask, and $1 \mathrm{ml}$ Hydroxylamine and $2 \mathrm{ml}$ conc. $\mathrm{HCl}$ were added. The sample was boiled until the volume reduced to $15 \mathrm{ml}-20 \mathrm{ml}$. Then, the sample was taken into a $50 \mathrm{ml}$ flask and $1 \mathrm{ml}$ of 1-10 phenanthroline and $10 \mathrm{ml}$ ammonium acetate buffer were added. Then, distilled water was added up to the mark. Then, the sample was allowed to develop the maximum color change within $10-15$ minutes. Figure 4 depicts the samples of supernatant prepared for the analysis.

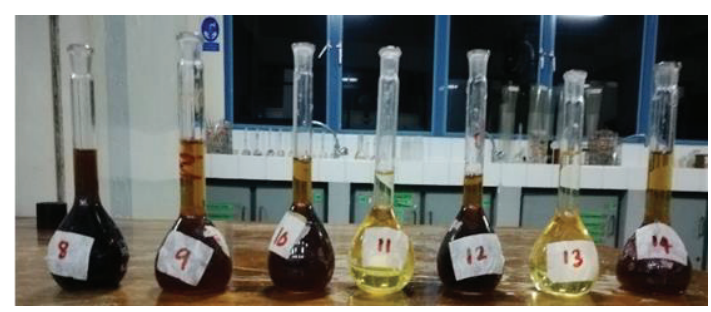

Figure 4 - The Samples of Supernatant Prepared for the Analysis

\subsection{Plotting Adsorption Isotherms}

The adsorption isotherm experiments results were checked with several adsorption isotherm models such as Langmuir, Freundlich, Temkin and Elovich in order to obtain the theoretical maximum adsorption capacities. All adsorption data were better fitted with Langmuir isotherm model than other isotherm models. The 
Langmuir isotherm model is based on two assumptions as follows: a fixed number of accessible sites are available on the adsorbent surface, all of which have the same energy; and the adsorption is reversible [15]. Equation 1 describes the Langmuir isotherm modal, where, $\mathrm{x} / \mathrm{m}$ - Mass of adsorbate adsorbed per unit mass of adsorbent (mg/g);

a - Maximum adsorption capacity $(\mathrm{mg} / \mathrm{g})$;

$\mathrm{b}$ - Empirical constant related to the adsorption energy $(l / m g)$; and

$\mathrm{C}_{\mathrm{e}}$ - Equilibrium concentration of the adsorbate in the solution after adsorption $(m g / l)$.

$\mathrm{C}_{\mathrm{e}} /(\mathrm{x} / \mathrm{m})=1 / \mathrm{ab}+\mathrm{C}_{\mathrm{e}} / \mathrm{a}$

\section{Results and Discussion}

\subsection{Kinematic Experiments}

The adsorption data for the uptake of total iron versus contact time for a fixed adsorbent dose of $40 \mathrm{~g} / \mathrm{l}$ are shown in Figure 5. These plots indicate that the removal efficiencies of total iron in both $\mathrm{CW}, \mathrm{BMW}$ and RW have reached its maximum values and remained more or less constant, while that in FW slightly decreased with contact time. The results indicate that the maximum removal efficiencies of total iron were 90.5\%, $96.5 \%, 97.5 \%$ and $94.4 \%$ for CW, BMW, FW and RW with the contact time periods of $12 \mathrm{~h}, 8 \mathrm{~h}$, $2 \mathrm{~h}$ and $8 \mathrm{~h}$, respectively. Hence, all the materials are able to remove the total iron from the landfill-leachate at an efficiency of more than $90 \%$.

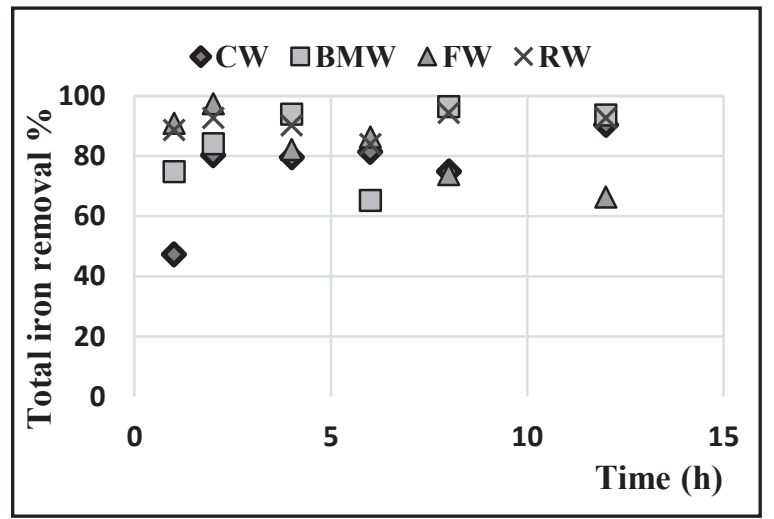

Figure 5 - Total Iron Removal Efficiency Vs Contact Time

\subsection{Adsorption Isotherm Experiments}

The effect of adsorbent dose on the removal of total iron is shown in Figure 6. The adsorbent dose was increased from 8 to $60 \mathrm{~g} / \mathrm{l}(2 \mathrm{~g}, 4 \mathrm{~g}, 6 \mathrm{~g}$, $8 \mathrm{~g}, 10 \mathrm{~g}$ and $15 \mathrm{~g}$ ) and the adsorption took place with a notable change. The expected result was that the removal efficiency would increase with the increment of the mass, leading to the increment of vacant sites to adsorb iron. However, the decrease in the adsorption with the high adsorbent dose could be caused by partial aggregation of adsorbent, which decreases the effective surface area for metal uptake [16]. The results obtained confirmed that the selected dose range from $8 \mathrm{~g}$ to $10 \mathrm{~g}$ is sufficient for the optimum removal of the total iron, and no further increment of the dose would be essential. The maximum adsorption of total iron occurred at an adsorbent dosage of $8 \mathrm{~g}$, $10 \mathrm{~g}, 6 \mathrm{~g}$ and $10 \mathrm{~g}$ for CW, FW, BMW and RW with the removal efficiencies $99.6 \%$, 97.8\%, $97.9 \%$ and $95.3 \%$, respectively with the particle size of $0.425 \mathrm{~mm}$ at $25^{\circ} \mathrm{C}$.

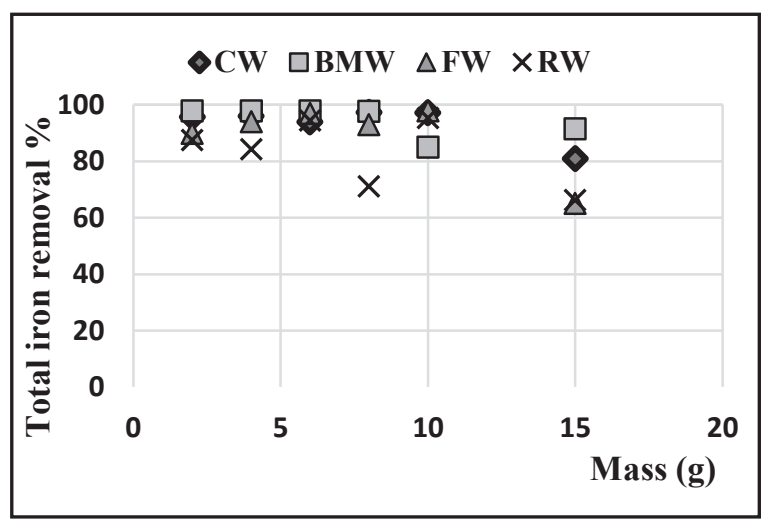

Figure 6 - Total Iron Removal Efficiency Vs Adsorbent Dose

The variation of $\mathrm{pH}$ of the supernatant for the adsorption isotherm experiments conducted for each material is illustrated in Figure 7 . Compared to initial $\mathrm{pH}$ of the influent $(\mathrm{pH}=2)$, $\mathrm{pH}$ of the supernatants of CW, BMW and FW after the experiments increased. This could be due to the alkaline nature of these materials. $\mathrm{pH}$ of the supernatant of each material slightly increased with the increase of the adsorbent dosage. $\mathrm{pH}$ of $\mathrm{RW}$ remained more or less close to that of the influent.

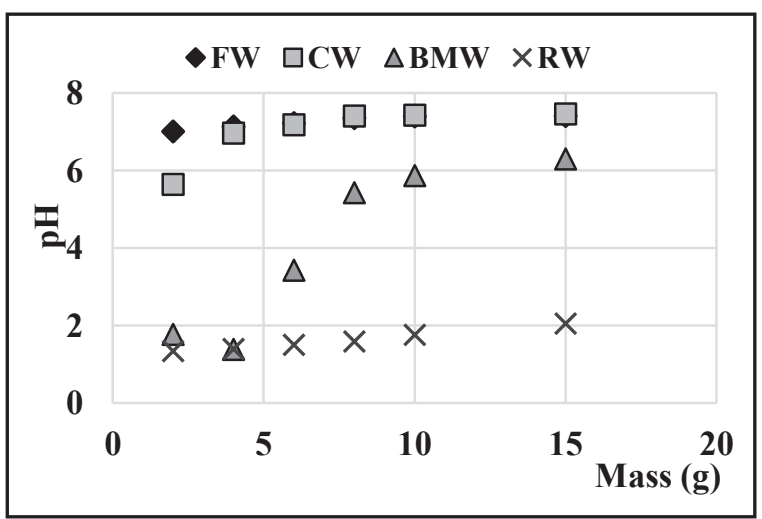

Figure 7 - Variation of $\mathrm{pH}$ in the Supernatants of the Adsorption Isotherm Experiment

Figure 8 illustrates the variation of ORP (Oxidation Reduction Potential) with the adsorbent dosage in the supernatant of 
adsorption isotherm experiments for each reactive material. The ORP of the supernatant of FW and CW were lower than that of the adsorbate, indicating that the oxidation reactions had surpassed reducing reactions. In BMW, at the optimum mass of $6 \mathrm{~g}$, the resultant redox reaction could be the 'reduction' as the ORP had increased more than that of the adsorbate. In RW, the ORP was higher in the supernatants than that of the adsorbate for all the masses of adsorbent, implying reduction reactions to have been the net effect of the redox reactions. When the adsorbent dosage increased, the ORP values decreased for all materials.

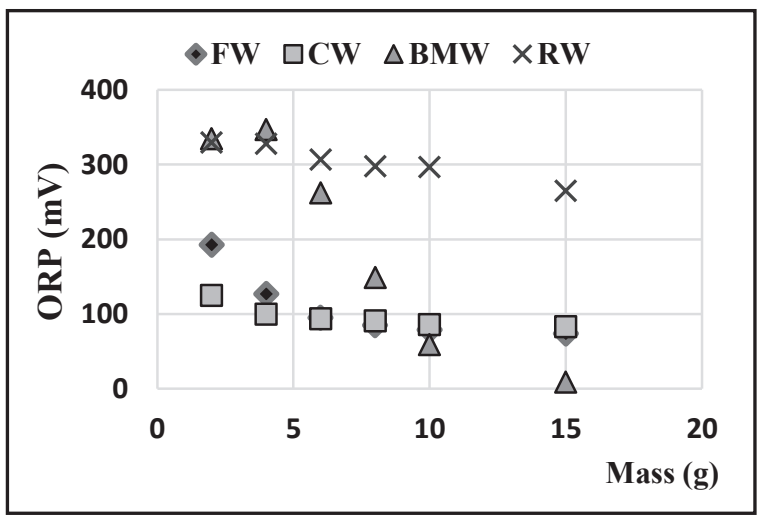

Figure 8 - Variation of ORP in the Supernatants of the Adsorption Isotherm

Figure 9 depicts the variation of conductivity of the supernatants during the adsorption isotherm experiment for each adsorbent material. The conductivity remained more or less constant with the increase of the mass of adsorbent.

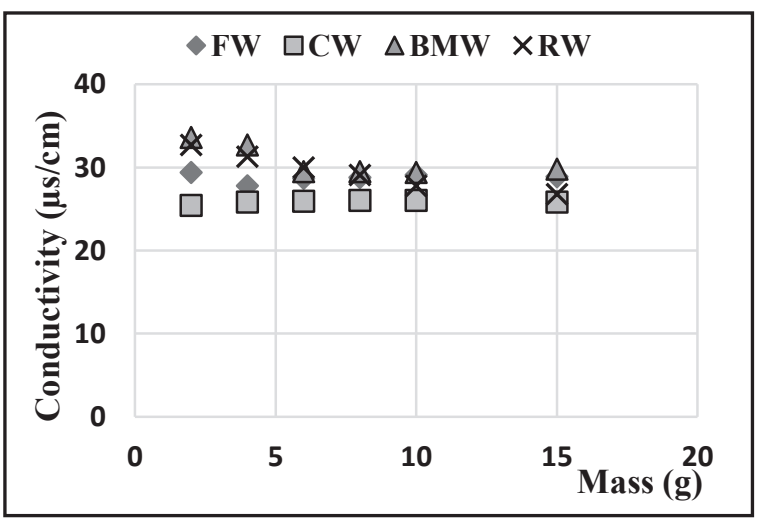

Figure 9 - Variation of Conductivity in the Supernatants of the Adsorption Isotherm Experiment

3.3 Effect of the Initial Iron Concentration The effect of initial iron concentration on the removal efficiency of total iron on BMW was studied using different initial iron concentrations $(25 \mathrm{mg} / \mathrm{l}-200 \mathrm{mg} / \mathrm{l})$ (Figure 10).
The adsorption of total iron highly depends on the initial iron concentration. The plot shows that the total iron removal efficiency increased with the increase of the initial iron concentration.

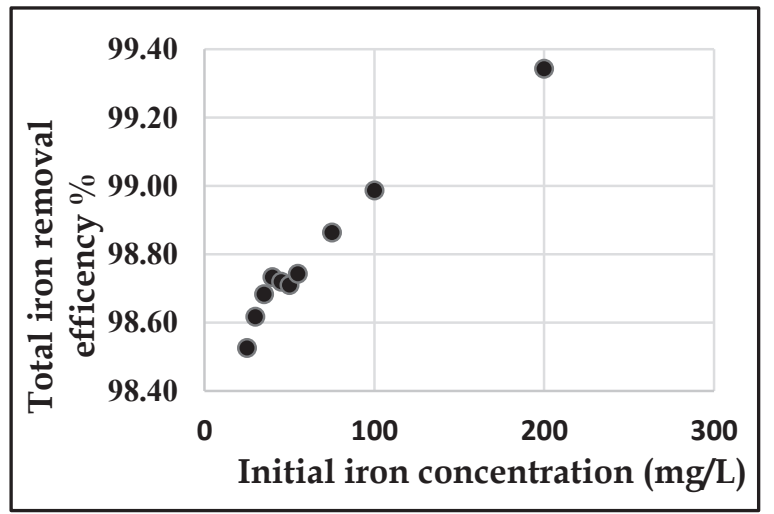

Figure 10 - Effect of Initial Iron Concentration $\left(25^{\circ} \mathrm{C}, 400 \mathrm{rpm}\right.$, Adsorbent Dose 6 g, Contact Time 8 h, pH 2)

Figure 11 depicts the relationship between the amount of total iron adsorbed with the initial iron concentration. The adsorbed amount is directly proportional to the initial iron concentration.

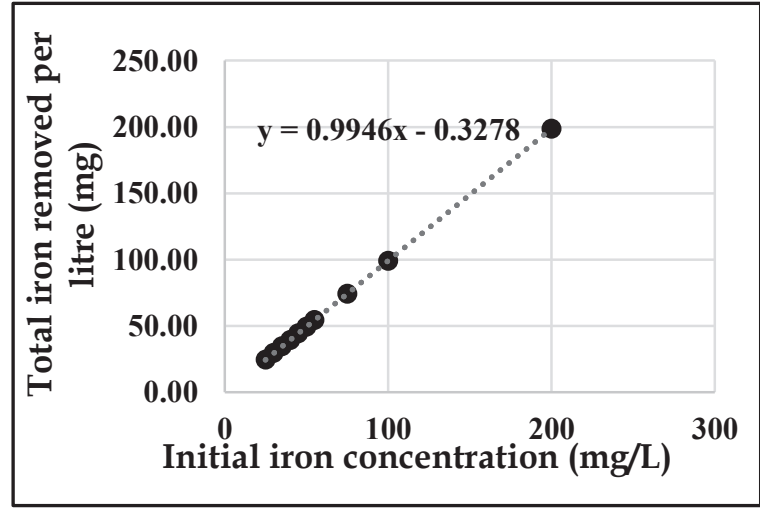

Figure 11 - Total Iron Removed with Initial Iron Concentration

\subsection{Effect of Initial $\mathbf{p H}$}

$\mathrm{pH}$ of the adsorbate is one of the important factors which affects the adsorption of metal ions. The effect of initial $\mathrm{pH}$ of the adsorbate was studied in the range of $2-8$. The lower range of $\mathrm{pH}$ was obtained by adding $\mathrm{HNO}_{3}$ drop by drop. As shown in Figure 12, the maximum adsorption of total iron took place at an initial $\mathrm{pH}$ of 8 . At lower $\mathrm{pH}, \mathrm{H}^{+}$ions compete with metal cations for the available adsorption sites, whereas adsorption site does not activate at higher $\mathrm{pH}[4]$. 


\subsection{Effect of Temperature}

The effect of temperature on the removal of total iron is illustrated in Figure 13. This plot depicts that the amount absorbed increased with the increase of temperature. This indicates the endothermic nature of the adsorption process.

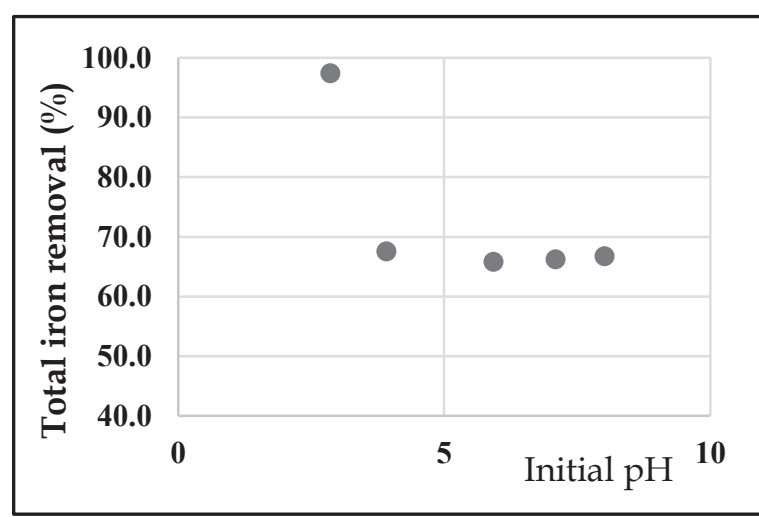

Figure 12 - Effect of Initial pH of the Solution $\left(25^{\circ} \mathrm{C}, 400 \mathrm{rpm}\right.$, Adsorbent Dose 6 g, Contact Time 8 h)

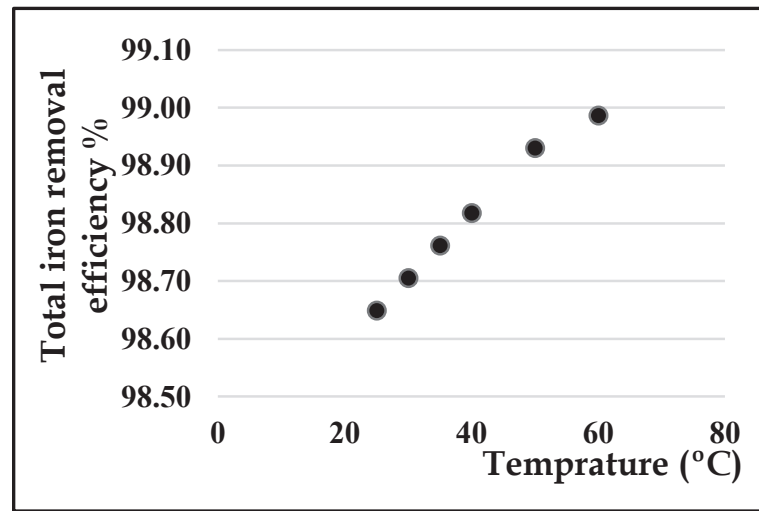

Figure 13 - Effect of Temperature on the Adsorption of Total Iron (400 rpm, Adsorbent Dose 6 g, Contact Time 8 h, pH 2)

\subsection{Adsorption Isotherms}

The results obtained for the removal of total iron were analyzed by the well-known adsorption isotherm models, Langmuir, Freundlich, Temkin and Elovich. Langmuir isotherm fitted well with the experimental data. Figures 14, 15, 16 and 17 show the plots of Langmuir isotherm models for CW, RW, BMW and FW, respectively. The maximum adsorption capacity of building waste, termed as Langmuir complete monolayer coverage, indicates that $1 \mathrm{~g}$ of $\mathrm{FW}$, CW, BMW and RW, can adsorb 0.43, 0.84, 0.17 and $0.43 \mathrm{mg}$, respectively. All these materials have adsorption capacities in terms of $\mathrm{mg} / \mathrm{g}$ in the order of magnitude equal to -1 . Table 1 shows the best fitted isotherm characteristics for each material. Table 2 compares the adsorption capacity of building waste for total iron with those of a few other low-cost adsorbents.

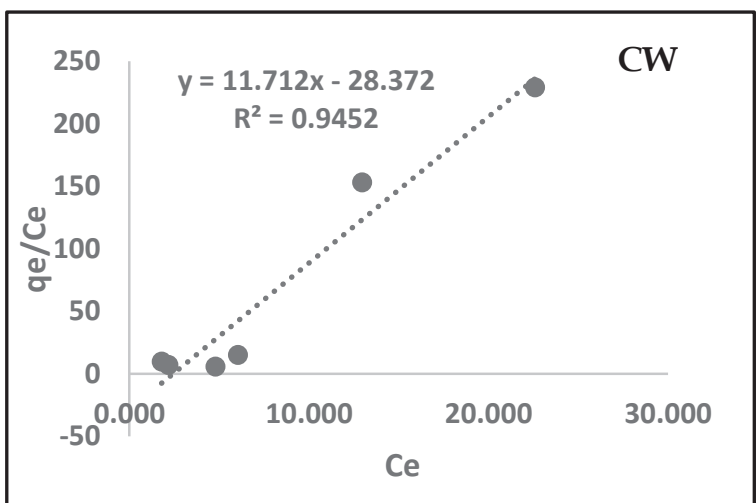

Figure 14 - Plot of Langmuir Isotherm Model for $\mathrm{CW}$

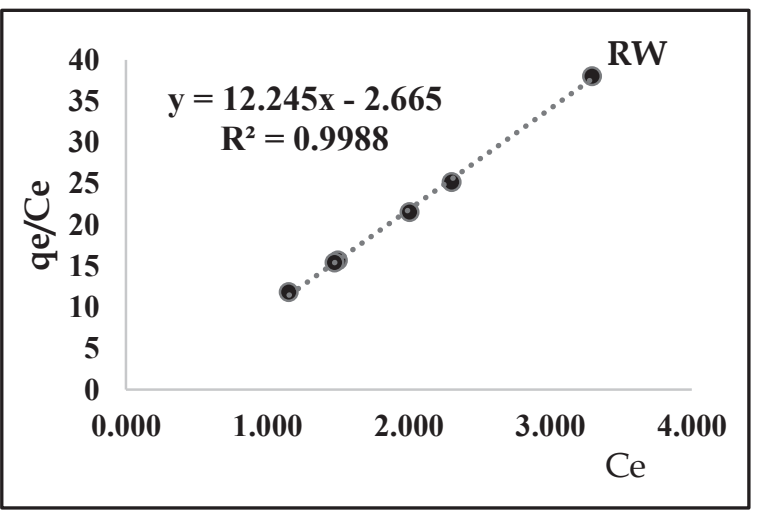

Figure 15 - Plot of Langmuir Isotherm Model for RW

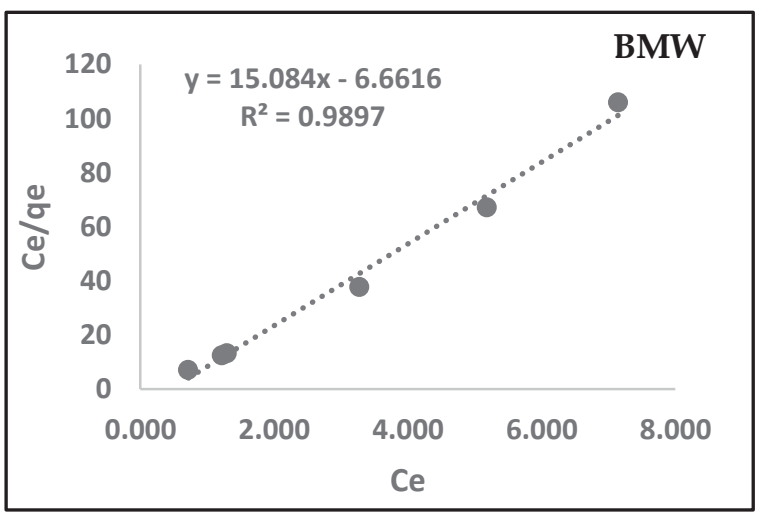

Figure 16 - Plot of Langmuir Isotherm Model for BMW

Table 1 - Langmuir Isotherm Parameters for Each Adsorbent

\begin{tabular}{lccc}
\hline & $\mathrm{R}^{2}$ & $\mathrm{a}(\mathrm{mg} / \mathrm{g})$ & $\mathrm{b}(\mathrm{l} / \mathrm{mg})$ \\
\hline CW & 0.97 & 0.42 & 1.02 \\
BMW & 0.95 & 0.84 & 2.12 \\
FW & 0.99 & 0.17 & 0.59 \\
RW & 0.95 & 0.43 & 0.41
\end{tabular}




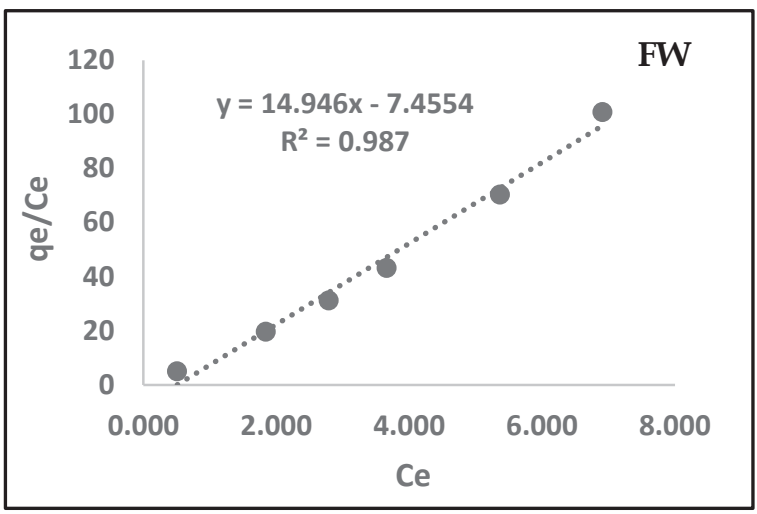

Figure 17 - Plot of Langmuir Isotherm Model for FW

Table 2- Comparison of Adsorption Capacity of Building Waste with Other Adsorbents for Total Iron

\begin{tabular}{lccc}
\hline Adsorbent & $\mathrm{a}(\mathrm{mg} / \mathrm{g})$ & $\mathrm{R}^{2}$ & Reference \\
\hline $\begin{array}{l}\text { Coconut } \\
\text { husk }\end{array}$ & 0.0009 & $\begin{array}{c}0.919 \\
0\end{array}$ & {$[12]$} \\
$\begin{array}{l}\text { Chitosan } \\
\text { beads }\end{array}$ & 64.10 & $\begin{array}{c}0.998 \\
6\end{array}$ & {$[9]$} \\
$\begin{array}{l}\text { Brick and } \\
\text { mortar } \\
\text { waste }\end{array}$ & 0.84 & $\begin{array}{c}0.945 \\
5\end{array}$ & $\begin{array}{c}\text { Current } \\
\text { study }\end{array}$ \\
\hline
\end{tabular}

\section{Conclusion}

All types of building waste tested in the present study have excellent adsorption capacities for total iron present in landfill-leachate. The adsorption data fit very well with Langmuir model than Freundlich and Temkin models. The adsorption was found to be endothermic in nature. The maximum adsorption capacity of building waste, termed as Langmuir complete monolayer coverage, indicates that $1 \mathrm{~g}$ of $\mathrm{FW}$, CW, BMW and RW, can absorb 0.43, 0.84, 0.17 and $0.43 \mathrm{mg}$, respectively. The adsorption capacities $(\mathrm{mg} / \mathrm{g})$ of all the materials tested in the present study are in the order of magnitude equal to -1 , whereas the order of magnitude of the adsorption capacity of coconut husk is -4 .

There exist some relationships between sorption properties and the structure of the adsorbate or the surface properties and the groups of adsorbents besides the surface area/porosity effect [7]. The agitation speed and particle size are also important factors to determine the treatment efficiency. Though, both the above factors were selected based on a few past research, the selected values can be considered quite arbitrary. Hence, further experiments are recommended to understand the adsorption characteristics between building waste and total iron contained in landfill-leachate.
The long-term operation of these materials may make them not suitable for absorption of heavy metals. Therefore, it is also recommended to conduct laboratory-scale column experiments, bench-scale experiments, pilot and field-scale experiments to investigate the hydraulic and mechanical properties of these materials, which would decide the longevity of their application.

\section{Acknowledgement}

The authors acknowledge the assistance extended by Ms. Nimal Shanthi, Technical Officer of the Environmental Engineering Laboratory of the Department of Civil and Environmental Engineering, Faculty of Engineering, University of Ruhuna.

\section{References}

1. Vaux, H., "Groundwater Under Stress: The Importance of Management", Environ Earth, Volume 62, 2011, pp. 19 - 23.

2. Higgens, M. R., "Environmental Assessment of in Situ Groundwater Remediation with Reduced Iron Reactive Media," University of Michigan: s. n, 2011.

3. Alrumman, S. A., El-kott, A. F. and Keshk, S. M., "Water Pollution: Source \& Treatment.", American Journal of Environmental Engineering, 6(3), 2016, pp.88-98.

4. Nesaratnam, S. T. ed., Water Pollution Control, John Wiley \& Sons, 2014.

5. Rowe, R. K., "Leachate Characteristics for MSW Landfills", University of Western Ontario, Department of Civil Engineering, Faculty of Engineering Science,1995.

6. Abhayawardana, G. P. R., "Removal of Lead in Landfill Leachate Using Permeable Reactive Barriers with Natural Red Earth and Peat", Engineer: Journal of the Institution of Engineers, Sri Lanka, 48(4), 2015.

7. Zhao, G., Wu, X., Tan, X. and Wang, X. "Sorption of Heavy Metal Ions from Aqueous Solutions: A Review", The Open Colloid Science Journal, 4(1), 2010.

8. Eding, E. H., Kamstra, A., Verreth, J. A. J., Huisman, E. A. and Klapwijk, A., “Design and Operation of Nitrifying Trickling Filters in Recirculating Aquaculture: A Review", Aquacultural Engineering, 34(3), 2006, pp.234-260. 
9. Ngah, W. W., Ab Ghani, S. and Kamari, A.,

"Adsorption Behaviour of Fe (II) and Fe (III) Ions in Aqueous Solution on Chitosan and Cross-linked Chitosan Beads", Bioresource Technology, 96(4), 2005, pp.443-450.

10. Koutcheiko, S., Monreal, C. M., Kodama, H., Mc Cracken, T. and Kotlyar, L., "Preparation and Characterization of Activated Carbon Derived from the Thermo-Chemical Conversion of Chicken Manure", Bioresource Technology, 98(13), 2007, pp.2459-2464.

11. Hegazi, H. A., "Removal of Heavy Metals from Wastewater Using Agricultural and Industrial Wastes as Adsorbents". HBRC Journal, 9(3), 2013, pp.276-282.

12. Agbozu, I. E. and Emoruwa, F. O., "Batch Adsorption of Heavy Metals $(\mathrm{Cu}, \mathrm{Pb}, \mathrm{Fe}, \mathrm{Cr}$ and $\mathrm{Cd}$ ) from Aqueous Solutions Using Coconut Husk", African Journal of Environmental Science and Technology, 8(4), 2014, pp.239-246.

13. Bronstein, K., Permeable Reactive Barriers for Inorganic and Radionuclide Contamination, National Network of Environmental Management Studies Fellow, 2005.

14. Standard Methods for the Examination of Water and Wastewater, American Public Health Association, 1015 Fifteenth Street, NW, Washington, DC, USA, 1988, pp. 200052605.

15. Dada, A. O., Olalekan, A. P., Olatunya, A. M. and Dada, O., "Langmuir, Freundlich, Temkin and Dubinin-Radushkevich Isotherms Studies of Equilibrium Sorption of Zn2+ Unto Phosphoric Acid Modified Rice Husk", IOSR Journal of Applied Chemistry, 3(1), 2012, pp.38-45.

16. Anwar, J., Shafique, U., Waheed-uzZaman, Salman, M., Dar, A., Anwar, S., "Removal of $\mathrm{Pb}$ (II), and Cd (II) from Water by Adsorption on Peels of Banana", Bioresource Technology, Volume 101, 2010, pp. 1752 - 1755. 